\title{
LAPAROSCOPIC VERSUS OPEN APPENDECTOMY: RETROSPECTIVE COMPARISON IN RURAL URBAN SETTINGS
}

\author{
Manisha Nigam¹, T.P. Devpura², Brijendra Nigam³ ${ }^{3}$ Renu Ranwaka4, Chitra Rani Chauhan ${ }^{5}$
}

\section{HOW TO CITE THIS ARTICLE:}

Manisha Nigam, T.P. Devpura, Brijendra Nigam, Renu Ranwaka, Chitra Rani Chauhan. "Laparoscopic versus Open Appendectomy: Retrospective Comparison in Rural Urban Settings". Journal of Evolution of Medical and Dental Sciences 2014; Vol. 3, Issue 05, February 03; Page: 1230-1234, DOI: 10.14260/jemds/2014/1973

ABSTRACT: OBJECTIVE: This retrospective comparative study was undertaken from data of various peripheral centers of Kanpur and around, to assess the impact of Laparoscopic Appendectomy on the patients care where prior to it, conventional open appendectomy (OA) was in vogue. PATIENTS AND METHODS: This retrospective study was done on the patients who were operated by different surgeons in different peripheral hospitals for appendectomy during period of 36 months (from Dec 2010 to Nov 2013).Total data of 360 patients collected out of which the number in each group of patients who underwent laparoscopic appendectomy and patients who had open procedure kept same i.e. 180. Each patient's data was selected in a non-randomized fashion. Both groups were studied for length of hospital stay, operating time, complications and conversion rate and cost involved (consumables only). RESULTS: Analysis of both groups within same interim period showed same age/sex distribution and diagnosis was made mainly on clinical grounds supported by hematological and ultra-sonology tests. Within the laparoscopic group, average length of stay was 3.14 (2-4) days, compared with 4.19 (2-7) days of open appendectomy. Operating time for laparoscopic group was 1.02 (1-1.5) hours with only six conversion into Lanz incisions. In the open group the operating time was $51.5 \mathrm{~min}$ (30-90min) and there were 40 laparotomies due to uncertain diagnosis, in three cases due to extensive adhesions appendectomy could not be performed. 28 of these cases also required adjunctive imaging for diagnostic purposes. CONCLUSIONS: This study identified the value of the laparoscopic technique for appendectomy in a non-specialist center. This benefits the patients with low morbidity, shorter hospital stay, minimal operating time and quicker recovery. Cost factors and expertize available however refrain these peripheral hospitals to adopt laparoscopic appendectomy as routine procedures. But these results show that practice of LA also inspired the practitioners of low experience to take on this procedure with confidence and maintain their laparoscopic skills which potentially could be utilized for other related laparoscopic operations.

KEYWORDS: Laparoscopic appendectomy, acute appendicitis, wound infection.

INTRODUCTION: Acute appendicitis is the most common surgical emergency encountered to surgeons. The diagnosis of acute appendicitis is mainly clinical. These days with advent of newer antibiotics virgin cases of acute appendicitis becomes rare and produces diagnostic dilemma. Although it is one of the most common surgical emergencies, the preoperative clinical diagnosis of appendicitis is reported to be correct in only $60-80 \%$ of the cases. ${ }^{1}$ So, even in this era of technological advancements, the appendicitis continues to be more of a clinical diagnosis. Appendicitis is the most common intra-abdominal emergency with a life time risk of $6 \% .{ }^{2}$ for more than a century, open appendectomy (OA) remains the treatment of choice in acute appendicitis. The advent of endoscopic surgery led to the idea of performing laparoscopic appendectomy (LA). Kurt Semm a German gynecologist performed the first LA in $1981 .^{3}$ There are three main problems with 
conventional open appendectomy - namely a misdiagnosis rate of $15-30 \%$ (up to $50 \%$ in females in the reproductive age group), wound infection rate $5-10 \%$, and postoperative adhesions.

This can be reduced to minimum by LA, by performing laparoscopic diagnosis. The other advantages are same as in other laparoscopic procedures like quick recovery, less hospital stay, less postoperative pain, fewer postoperative complications and better cosmesis especially in females. LA is carried out with enthusiasm in many specialist centers but its application in peripheral centers is not as popular due to a variety of reasons main being unavailability of expertize, high investment cost for laparoscopic operations setup and higher cost of consumables in LA as compared to OA. This retrospective comparative study was undertaken from the source data from various peripheral center of urban and rural setting to assess its impact on the service where, prior to this operation was conventional.

PATIENTS \& METHODS: This retrospective comparative study was carried out at Rama Medical College Hospital and Research center Kanpur. The data was collected from the Hospital itself and from various other centers situated in nearby periphery between period of 36 months from December 2010 to Nov.2013.

The patients were randomly divided into LA and OA groups. The data of total 360 patients were taken for appendectomy (both LA \& OA) during the same period. Appendectomy performed during diagnostic laparoscopy for another indication and incidental appendectomies were excluded. Laparoscopic appendectomies were done using a standard approach involving an open technique for trocar insertion. Operative time was calculated from the time of incision until the time of closure and did not reflect the time required to set up the laparoscopic equipment. Both groups were studied for length of hospital stay, operating time, complications, conversion rate and expenses in terms of consumables.

RESULTS: Analysis of both groups within same interim period showed same age/sex distribution and clinical presentation. Within the laparoscopic group, average length of stay was 3.14 days, compared with 4.1 days of 0 .

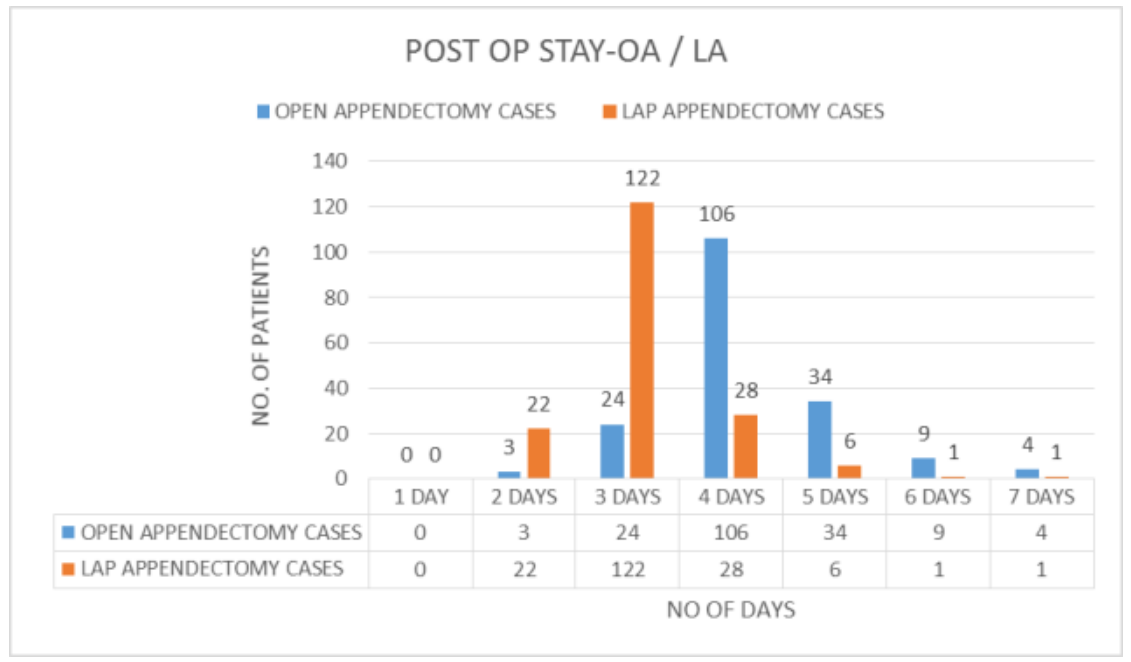




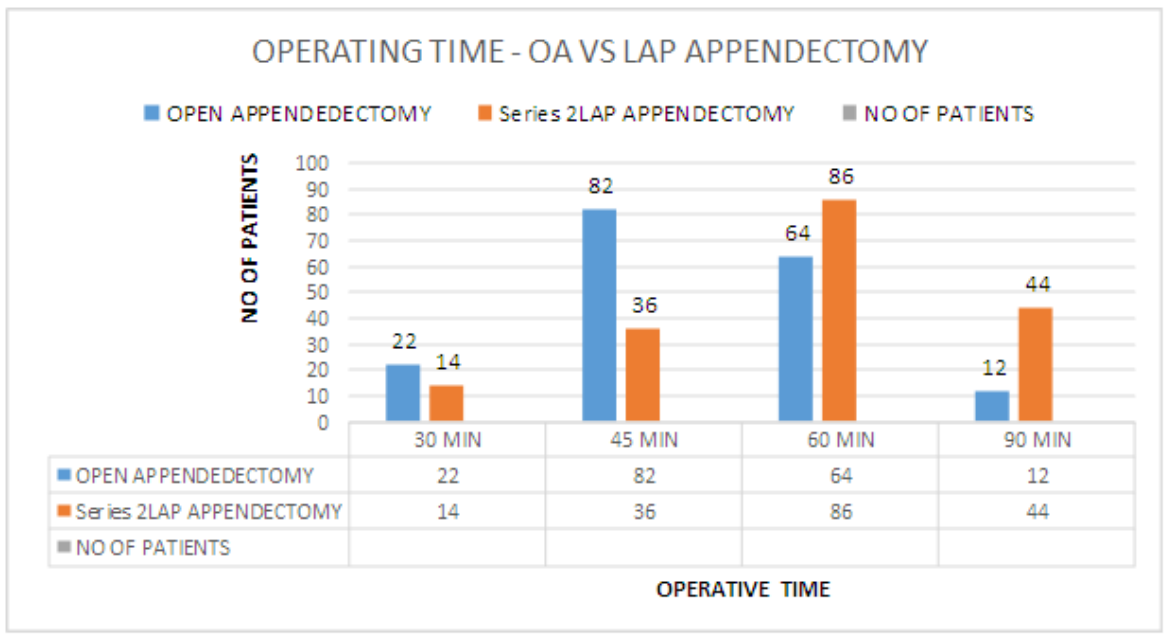

Operating time for laparoscopic group was 1.02(1-1.5) hours with only six conversion into Lanz incisions. In the open group the operating time was $51.5 \mathrm{~min}(30-90 \mathrm{~min})$ and there were 40 laparotomies due to uncertain diagnosis, in three cases due to extensive adhesions appendectomy could not be performed. 28 of these cases also required adjunctive imaging for diagnostic purposes. In $\mathrm{OA}$ group, two patients had pelvic abscess during their stay in hospital which was subsequently drained under ultrasound guidance. The average consumable cost for open and laparoscopic cost however varied and cannot be enumerated here in this study but as a whole consumables cost in LA is double to that of Open group.

DISCUSSION: Appendix is considered as vestigial organ but has been a source of surgical emergency from time unknown. In1889, Charles Mc.Burney published the first of the several papers on standard clinical approach to the diagnosis and treatment of appendicitis. Since then, the surgical approach for appendicitis has remained nearly unchanged. Medicine is changing every day. Laparoscopy brought new dimensions to surgery. The widespread use of laparoscopic techniques by general surgeons has changed the surgical approach. The advantage of laparoscopic surgery for abdominal conditions, compared with their conventional counterparts in terms of decreased postoperative pain, shorter hospital stay, shorter duration on convalescence, and rapid return to normal daily activities, have made laparoscopic approaches increasingly popular among surgeons and patients. Despite recent advances in technology, there is no laboratory test or examination with sufficient specificity and sensitivity to diagnose appendicitis consistently. There have been numerous attempts to improve the diagnostic accuracy and outcome of patients with acute appendicitis. The negative appendectomy rate in most series is still in the range of $20 \%$ to $30 \%{ }^{4-6}$ Because of this, LA unlike other laparoscopically adapted procedures such as colonic resection, hernia repairs, splenectomy, nephrectomy have not gained such widespread acceptance since benefits of this laparoscopic procedure is still not self-evident. ${ }^{7}$

The first largest series of laparoscopic appendectomy, performed for acute Appendicitis came from Germany and was published by Pier and colleagues in 1991.8 These surgeons demonstrated laparoscopic appendectomy which could be applied to most cases of appendicitis, with a high degree of success, a low complication rate, and an operative speed as fast as open appendectomy. ${ }^{8}$ The mean operating time in LA group was higher than that was in patients undergoing OA. In this study, the 
mean operating time was about 40 minutes in $\mathrm{OA}$ as compared to 1.08 hours in LA group. These findings are consistent with some other studies reporting though significant variations in operating have been noted in various controlled studies. ${ }^{9-15}$ Comparisons between length of stay after LA and $\mathrm{OA}$ has been a debatable issue in recent past. The literature search provides contradictory results.

The average length of stay in LA was 3.03 days as compared to 4.01 days in OA group. In a nonrandomized trial of 122 patients Schirmer et al found no significant difference in hospital stay. ${ }^{16}$ Some recent retrospective cohort studies ${ }^{17-19}$ shows a significant shorter hospital stay after LA while other shows no significant differences in hospital stay.20,21

CONCLUSION: This study identified the value of the laparoscopic technique for appendectomy in a non-specialist center. This benefits the patients with its low morbidity, shorter hospital stay, minimal operating time and quicker recovery. This practice also inspired the practitioners of low experience to take on this procedure with confidence and maintain their laparoscopic skills which potentially could be utilized for other related laparoscopic operations. As far as the economics part of the procedures is concerned that can be brought down by its extensive application. If states are ready to adopt these procedures in govt. owned hospitals and train their surgeons for this procedure, this well-established superior procedure will entirely replace the old conventional appendectomies until required otherwise and ultimate benefit will be transferred to poor patients as well.

\section{REFERENCES:}

1. Fergusson JAE, Hitos K, Simpson E. Utility of white cell count and ultrasound in the diagnosis of acute appendicitis. ANZ J Surg 2002; 72:781-5.

2. Samelson Sl, Reyes HM. Management of perforated appendicitis in children - revisited. Arch Surg. 1987; 122:691-6.

3. Semm K. Endoscopic appendectomy. Endoscopy.1983; 15:59- 64.

4. Long KH, Bannon MP, Zietlow SP, Helgeson ER, Harmsen WS, Smith CD et al. A prospective randomized comparison of laparoscopic appendectomy with open appendectomy.

5. Maxwell JG, Robinson CL, Maxwell TG, Maxwell BG, Smith CR, Brinker CC et al. Deriving the indications of laparoscopic appendectomy from a comparison of outcomes of laparoscopic and open appendectomy. Am J Surg. 2001; 182:687- 92.

6. Peiser JG, Greenberg D. Laparoscopic versus open appendectomy: results of a retrospective comparison in an Israeli hospital. Isr Med Assoc J. 2002; 4:91-2.

7. Filzgibbans RJ, Ulualp KM. Laparoscopic appendectomy. In: Mastery of Surgery, Nyhus LM, Baker RJ, Fisher JE, 3rd Ed, vol: II, Little Browns Company 1997; 1412-9.

8. Pier A, Gotz F, Bacher C. Laparoscopic appendectomy in 625 cases: from innovation to routine. Surg Gynecol Obstet. 1993 Nov; 177(5):473-80.

9. Khan MN, Fayyad T, Cecil TD, Moran BJ. Laparoscopic versus open Appendectomy: the risk of post-operative infectious complications. JSLS.2007;11: 363-7.

10. Yau KK, Siu WT, Tanq CN, Yanq GP, Li MK. Laparoscopic versus open appendectomy for complicated appendicitis. J Am Coll surg. 2007; 205: 60-5.

11. Pokala N, Sadhasivam S, Kiran RP, Parithivel V. Complicated appendicitis is the laparoscopic approach appropriate? A comparative study with open approach: outcome in a community hospital setting. Am Surg. 2007; 37:737-41. 
12. Kamal M, Qureshi KH. Laparoscopic versus open appendectomy. Pak J Med Res 2003; 42:23-6.

13. Guller U, Hervey S, Purves H, Muhlbaier LH, Peterson ED, Eubanks S et al. Laparoscopic versus Open appendectomy: outcomes comparison based on a large Administrative Database. Ann Surg. 2004; 239: 43 - 52.

14. Frazae RC, Roberts JW, Symmonds RE, Snyder SK, Hendricks JC, Smith RW et al. A prospective randomized trial comparing open versus Laparoscopic appendectomy. Ann Surg 1994; 219: 725 - 8. [ Discussion 728 - 31].

15. Cox MR, McCall JL, Toouli J, Padbury RT, Wilson TG, Wattchow DA et al. Prospective randomized comparison of open versus Laparoscopic appendectomy in men. World J Surg 1996;20: 263 - 6.

16. Schirmer BD, Schmeig RE Jr, Dix J, Edge SB, Hanks JB. Laparoscopic versus traditional appendectomy for suspected appendicitis. Am J Surg 1993; 165:670 - 5.

17. Kurtz RJ, Heimann TM. Comparison of open and Laparoscopic treatment of acute appendicitis. Am J Surg.2001;182:211-4.

18. Johnson AB, Peetz ME. Laparoscopic appendectomy is an acceptable alternative for the treatment of perforated appendicitis. Surg Endosc. 1998; 12:940-3.

19. Nazzal M, Ali MA, Turfah F, Kaidi A, Saba A, Pleatman M et al. Laparoscopic appendectomy: a viable alternative approach. J Laparoendosc Adv Surg Tech A. 1997; 7: 1-6.

20. Moberg AC, Montgomery A. Appendicitis: Laparoscopic versus conventional operation: a study and review of literature. Surg Laparosc Endosc. 1997; 7:459 - 63.

21. Fallahzadeh H. Should a Laparoscopic appendectomy be done? Am Surg. 1998; 64:231 - 3.

\section{AUTHORS:}

1. Manisha Nigam

2. T.P. Devpura

3. Brijendra Nigam

4. Renu Ranwaka

5. Chitra Rani Chauhan

\section{PARTICULARS OF CONTRIBUTORS:}

1. Assistant Professor, Department of Surgery, Rama Medical College.

2. Professor, Department of Surgery, Rama Medical College.

3. Assistant Professor, Department of Surgery, Rama Medical College.
4. Professor, Department of Surgery, Rama Medical College.

5. Assistant Professor/Statistician, Department of Statistics, Rama Medical College.

\section{NAME ADDRESS EMAIL ID OF THE CORRESPONDING AUTHOR:}

Dr. Manisha Nigam,

Rama Medical College Hospital and Research Centre, Mandhana, Kanpur - 208010.

E-mail: brijendramanisha@yahoo.com

Date of Submission: 11/01/2014.

Date of Peer Review: 12/01/2014.

Date of Acceptance: 20/01/2014.

Date of Publishing: 29/01/2014. 